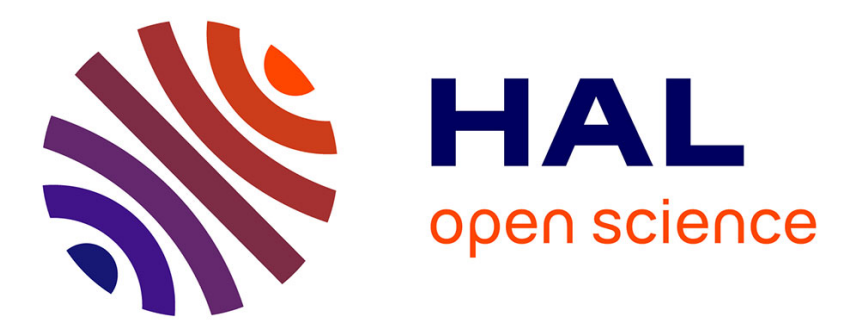

\title{
Assembly rules of helminth parasite communities in grey mullets: combining components of diversity
}

\author{
Cristina Llopis-Belenguer, Sandrine Pavoine, Isabel Blasco-Costa, Juan
}

Antonio Balbuena

\section{- To cite this version:}

Cristina Llopis-Belenguer, Sandrine Pavoine, Isabel Blasco-Costa, Juan Antonio Balbuena. Assembly rules of helminth parasite communities in grey mullets: combining components of diversity. International Journal for Parasitology, In press, 10.1016/j.ijpara.2020.06.006 . hal-02917105

\section{HAL Id: hal-02917105 \\ https://hal.science/hal-02917105}

Submitted on 18 Aug 2020

HAL is a multi-disciplinary open access archive for the deposit and dissemination of scientific research documents, whether they are published or not. The documents may come from teaching and research institutions in France or abroad, or from public or private research centers.
L'archive ouverte pluridisciplinaire HAL, est destinée au dépôt et à la diffusion de documents scientifiques de niveau recherche, publiés ou non, émanant des établissements d'enseignement et de recherche français ou étrangers, des laboratoires publics ou privés. 
1 Assembly rules of helminth parasite communities in grey mullets: combining components

2 of diversity

3 Cristina Llopis-Belenguer ${ }^{1 *}$, Sandrine Pavoine ${ }^{2}$, Isabel Blasco-Costa ${ }^{3}$, Juan Antonio Balbuena ${ }^{1}$

$4 \quad{ }^{1}$ Symbiosis Lab, Cavanilles Institute of Biodiversity and Evolutionary Biology, University of $5 \quad$ Valencia, PO Box 22085, 46071, Valencia, Spain

$6 \quad{ }^{2}$ Centre d'Ecologie et des Sciences de la Conservation (CESCO), Muséum National d'Histoire

7 Naturelle, CNRS, Sorbonne Université, CP 135, 43 rue Buffon, 75005 Paris, France

$8 \quad{ }^{3}$ Natural History Museum of Geneva, PO Box 6434, CH-1211 Geneva 6, Switzerland

$9 *$ corresponding author: tel. +34 963543 658; cristina.llopis.belenguer@ gmail.com

10 Note: Supplementary data associated with this article. 
Organisms associate themselves in ecological communities. It has been widely debated whether these associations are explained by deterministic or, in contrast, random processes. The answer may vary depending on the level of an organisational scale $(\alpha, \beta$ and $\gamma)$ and the facet of diversity considered: Taxonomic (TD), Functional (FD) and Phylogenetic (PD). Diversity at the sampling unit (i.e. host individual) is the $\alpha$ diversity; $\beta$ diversity represents the extent of dissimilarity in diversity among sampling units (within a level of an organisational scale, $\beta 1$; between levels of an organisational scale, $\beta 2$ ); and the total diversity of a system is $\gamma$ diversity. Thus, the combination of facets and levels of scale may be useful to disentangle the mechanisms driving the composition of a parasite community. Using helminth parasite TD, FD, and a Proxy of PD (PPD) of three species of grey mullets (Teleostei: Mugilidae) from the Mediterranean Sea, we show that random and deterministic processes of different nature explain the assemblage of parasite communities. The parasite community at a host individual $(\alpha)$ was invariably a random subset of the total diversity in the community for the three facets of diversity. At $\beta 1$ level, TD was lower than expected by chance, whereas FD and PPD were random. At $\beta 2$, diversity patterns suggested environmental filtering of the parasite assemblage: species, trait, and phylogenetic compositions of parasite communities seem to depend primarily on the species of host, but also on the locality and season. Our study shows that parasite communities are not totally understood if any of the components (i.e. facets and levels) of diversity is neglected.

\section{Keywords}

32 diversity; ecological communities; environmental filtering; helminths; limiting similarity; random processes 
Understanding the processes governing the distribution and assembly rules of biological diversity is one of the major challenges in biogeography and macroecology, and a prerequisite for successfully predicting global change impacts on biodiversity (Guisan and Rahbek, 2011). However, due to the extreme complexity of communities and ecosystems, we are still far from achieving this goal. The current state of affairs can be described as a schism between ecological and historical biogeography, which stems from the unresolved debate about the nature of the mechanisms governing community assembly. This divide, known as the Clements-Gleason controversy, has pervaded ecological thought for nearly a century. Whereas the Clementsian ecologists view ecological communities as tightly integrated entities consisting of interdependent species (the community-unit concept), the Gleasonians posit that species cooccur largely according to the individualistic response of each species to variable environmental conditions (the individualistic concept) (Liautaud et al., 2019). Accordingly, species would simply coexist because they tolerate the same habitat (Götzenberger et al., 2012; Liautaud et al., 2019). To a large degree, the latter view has prevailed in the last decades, based largely on empirical evidence of community composition along environmental gradients, and has eventually led to postulate the "disintegration of ecological community" (Ricklefs, 2008). Under this paradigm, species distributions would be mostly, if not exclusively, constrained by local environmental conditions, historical large-scale events, and dispersal capacity of the species. However, recent evidence suggests that community structure cannot be fully understood without taking into consideration deterministic processes, such as environmental filtering or limiting similarity (Pavoine and Bonsall, 2011).

Stochastic processes can affect diversity, influencing speciation, extinction, colonisation, or dispersal to a new community, and these can finally cause a random assemblage of diversity. On the other hand, deterministic processes can lead to either clustering (i.e. convergence) or overdispersion (i.e. divergence) of diversity (not to be confused with spatial clustering and overdispersion, Götzenberger et al., 2012). A clustering pattern of diversity assembly is interpreted as evidence of environmental filtering structuring the diversity of the 
community, because abiotic factors select individuals with particular environmental tolerances, and it results in similar life strategies converging in a community (Pavoine and Bonsall, 2011). In contrast, the opposite pattern, i.e. overdispersion, would reflect a limiting similarity process, in which biotic forces tend to limit the coexistence of very similar life strategies (Pavoine and Bonsall, 2011; Götzenberger et al., 2012). Nonetheless, environmental filtering and limiting similarity are not the only potential deterministic processes acting on communities and alternative processes can lead to similar patterns of diversity dispersal. For instance, competition due to biotic interactions excluding the less competitive strategies can also result in diversity overdispersion or clustering depending on the species affected in each situation (Mayfield and Levine, 2010).

The understanding of the processes that drive biological communities can be examined for the multiple components of diversity to get a complete resolution of communities. Diversity encompasses multiple levels (e.g. $\alpha, \beta, \gamma$ ) nested in organisational scales (e.g. spatial scales) and it has been argued that the importance of ecological processes is probably scale dependent. From the lowest to the highest of level of an organisational scale, three diversity levels are classically defined: $\alpha$ diversity or diversity at the sampling unit; $\beta$ diversity or extent of dissimilarity in diversity among sampling units (within a level of an organisational scale, $\beta 1$; between levels of an organisational scale, $\beta 2$ ) and $\gamma$ diversity or total diversity (Pavoine et al., 2016). Moreover, it includes multiple facets, such as the variety in species, traits, or evolutionary units (Pavoine and Bonsall, 2011). Regardless of the level considered, diversity has been studied under three facets: Taxonomic Diversity (TD, richness and abundance of taxonomic entities in a community), Functional Diversity (FD, richness and abundance of functional traits in a community) and Phylogenetic Diversity (PD, richness and abundance of genetically different entities in a community) (Pavoine and Bonsall, 2011). Traditionally, ecologists have considered TD as the single measure of diversity. This fact caused a continuous loss of ecological (FD) and evolutionary (PD) information, since TD considers that all the species in a community are equally similar and does not take into account the uniqueness of the functions or the phylogenetic distinctness of each species (Pavoine and Bonsall, 2011). 

diversity at different levels of organisation. The sampling unit (i.e. host individual) can be precisely defined (as required by Götzenberger et al., 2012) and it is often relatively easy to sample a large number of communities to eventually get strong statistical conclusions (Poulin and Valtonen, 2001). Although pioneering studies exist (e.g. Mouillot et al., 2005; Krasnov et al., 2014, 2015, 2016), up to now little is known about the mechanisms driving the different facets of diversity at different organisational scales of an entire parasite community. In studies of free-living organisms, assembly mechanisms of diversity can hierarchically be assessed at different spatial levels (e.g. local communities, regions, continents) or even temporal levels (e.g. years, decades, centuries) (Pavoine et al., 2009a). The study of parasite communities provides an additional organisational scale, the host, which also shapes parasite diversity. For example, on).

Here, we will investigate the assembly mechanisms (deterministic vs stochastic processes) of the helminth adult parasite communities of grey mullets (Teleostei: Mugilidae) from the Western Mediterranean Sea under the influence of host and environmental factors. This model is appropriate because, first, these parasite communities include parasite species from distant phylogenetic origins and are functionally disparate. Second, it comes from three that vary in their environmental parameters. This allows us to test whether the different facets of helminth diversity provide congruent results and whether host factors (phylogenetic proximity and similarity in life strategies) and/or environmental factors (geographical location and habitat conditions) select for different parasitic life strategies. Particularly, two of the host species, cephalus (Durand et al., 2012), whereas M. cephalus and C. ramada show greater similarities in 
their life strategies between them than with C. auratus (Cardona, 2001; Cardona, 2006). Additionally, our samples are from three coastal localities that differ in their habitat conditions (two marine: Ebro Delta, Sea - EDS and Santa Pola, Sea - SPS; and one brackish lagoon: Santa Pola, Lagoon - SPL) and in their geographical proximity (SPS and SPL are very close, $\sim 10 \mathrm{~km}$ apart; whereas EDS is more distant from the other two, $290 \mathrm{~km}$ ). Finally, our nested sampling design allows us to measure and compare diversity at the sampling unit ( $\alpha$ diversity or parasite diversity at the host individual) and among sampling units within and between levels of a factor (i.e. parasite diversity within ( $\beta 1)$ or between $(\beta 2)$ host individuals of a host species or locality).

We asked whether diversity patterns differ between the facets of parasite diversity and across two hierarchical scales (i.e. locality and host), and which are the factors (i.e. host phylogeny vs life strategies; habitat conditions vs geographic proximity) related to such variation. Based on evidence from free-living organisms (Cavender-Bares et al., 2006; Kraft and Ackerly, 2010), and previous studies of our host-parasite system (Blasco-Costa, 2009. Taxonomy of the Haploporinae Nicoll, 1914 and Bunocotylinae Dollfus, 1950 (Digenea) from Mediterranean mullets (Teleostei): morphological and molecular approaches. Doctoral dissertation, University of Valencia, Valencia, Spain; Blasco-Costa et al., 2012; Míguez-Lozano et al., 2012; Sarabeev et al., 2013), we hypothesise that both host phylogeny and host life strategy will influence the parasite community, whereas habitat conditions will be a stronger determinant of the parasite communities than the geographic distance. Parasite communities will be overdispersed at low organisational levels (within a locality or a host species) since similar life strategies will be limited (i.e. not able) to coexist. In contrast, at higher levels, we expect that clustering will be the driver of the parasite community, because the environment filters (i.e. selects for) certain life strategies.

\section{Material and methods}

\subsection{Data}

Fish were obtained from local harbour markets and surveyed for parasites as described in Blasco-Costa (2009. Taxonomy of the Haploporinae Nicoll, 1914 and Bunocotylinae Dollfus, 
147 approaches. Doctoral dissertation, University of Valencia, Valencia, Spain). Adults of helminth 148 parasites were identified following Yamaguti (1958), Gaevskaya and Dmitrieva (1992) and 149 Blasco-Costa (2009. Taxonomy of the Haploporinae Nicoll, 1914 and Bunocotylinae Dollfus, 1950 (Digenea) from Mediterranean mullets (Teleostei): morphological and molecular approaches. Doctoral dissertation, University of Valencia, Valencia, Spain) for 18 trematode species; Paperna (1964), Euzet and Combes (1969) and Sarabeev et al. (2013) for 9 monogenean species; Orecchia and Paggi (1987) for one nematode species; and Orecchia et al. (1988) and Tkach et al. (2014) for two acanthocephalan species. The dataset includes 272 host individuals and 30 parasite species from three seasons (two autumns and one spring) of two years (2004 and 2005) (Table 1). The Supplementary Material Table S1 contains the prevalence of the parasite species in each host species, locality, and season. Data analysis was entirely performed in R (R Core Team, 2019. R: A language and environment for statistical computing. $\mathrm{R}$ foundation for statistical computing, Vienna, Austria).

\subsubsection{Data accessibility}

Parasite abundance, functional traits and phylogenetic-like data analysed in this study and a step-by-step manual of the code, functions and packages used to analyse data and display figures are stored in DOI \#\#\#\#\#\# (https://github.com/crisLB/diversity). Thus, we expect to favour the reproducibility of our analyses and the expansion studies of parasite communities and to make future studies comparable under this framework.

\subsection{The multiple facets of diversity}

\subsubsection{Functional trait information}

The number of functional traits (i.e. features measurable at individual level which impacts the

171 fitness of individuals and reflects their performance in ecosystems) that can potentially be 172 assessed in any organism is large, but our ability to measure functional traits of parasites is often 173 limited. This is mainly due to technical impediments or lack of knowledge about the 
relationship between life-history information of the parasites and the components of fitness. Functional traits considered in this study conform to the definition of functional trait currently accepted in ecology (see above) and are susceptible to affect parasite fitness depending on environmental factors (see Table 2 in Llopis-Belenguer et al., 2019).

Here, we used five functional traits based on the framework and core list developed by Llopis-Belenguer et al. (2019): attachment organ, type of life cycle, body mass, egg size and number of eggs. We extracted information of categorial functional traits (i.e. attachment organ and type of life cycle) from direct observations, whereas, we obtained information of continuous functional traits (i.e. body mass, egg size and number of eggs) from species descriptions or as the mean value measured from a varying number of individuals of each species. To estimate individual body mass, we resorted to indirect methods "Area by Depth by Density" (for flatworms: trematodes and monogeneans) and "Volume of Revolution by Density" (for organisms with subcircular transversal section along their bodies: acanthocephalans and nematodes) (Llopis-Belenguer et al., 2018). Mass of a parasite species was computed as the mean mass of a range of individuals (mean number of individuals per species 9; range 2-12). Egg size was estimated as the mean maximum egg length and mean width from species descriptions when these measures were available. Otherwise, we measured these features from 3 to 20 eggs (mean 10) from a varying number of individuals from each species. Then egg volume $\left(\mu \mathrm{m}^{3}\right)$ was estimated assuming an ellipsoid shape (i.e. depth equal to width). For the number of eggs of monogeneans and trematodes, we counted eggs from 1 to 20 (mean 9) individuals per species mounted on slides. Since acanthocephalans and nematodes possessed too many eggs to be counted directly, the number of eggs was estimated as follows: 10 females of each species were dissected individually, and their eggs diluted in $1 \mathrm{ml}$ of saline solution each. Then the total number of eggs was estimated from aliquots of $0.1 \mathrm{ml}$ from each specimen. Regardless of the method used, we performed the procedure twice to obtain the mean number of eggs for each individual. Finally, we log-transformed data of continuous traits.

We built a functional trait (columns) by parasite species (rows) matrix with the dist.ktab function from package ade4 (Thioulouse et al., 2018) and calculated the Gower's distance 
202 (Gower, 1971) between species. This distance allows combining several types of traits

203 (continuous and categorical as described above) and incorporating observations with missing 204 data (4\% in our dataset). Then, we transformed the Gower matrix of pairwise distances into 205 Euclidean pairwise distances (function lingoes in ade4) and divided the resulting matrix by its maximum to bound values between 0 and 1 (Pavoine et al., 2009b).

\subsubsection{Proxy of phylogenetic diversity}

\subsubsection{Correlation between functional trait and taxon-level distances}

We assessed the correlation between the matrix of pairwise functional distances and the matrix of pairwise phylogenetic distances to study the relationship between the evolutionary history and ecological processes behind community assembly (Pavoine and Bonsall, 2011). We tested such correlation by means of the Mantel test (mantel function in vegan). 
Our samples were organised by three key factors: host species, locality, and season (Table 1).

Since C. auratus does not naturally occur in SPL, we evaluated the effect of the host species and the locality by splitting the diversity analyses into two case studies. In Case 1, we assessed the influence of host species on the three facets of diversity. To that end, we analysed and compared TD, FD and PPD of the helminth parasite communities from the three host species, at SPS in two autumn surveys (2004 and 2005). In Case 2, we evaluated the effect of locality and season survey on the parasite communities. To that end, we analysed and compared TD, FD and PPD of the helminth parasite communities from M. cephalus at the three localities surveyed in spring and autumn 2005 .

\subsubsection{Influence of one factor on diversity}

In both case studies, we measured diversity in two different ways. First, we used the Double Principal Coordinate Analysis (DPCoA) (Pavoine et al., 2004), that is a combined version of the Rao index of diversity (Rao, 1982) and the Weighted Principal Coordinate Analysis (Gower and Legendre, 1986). DPCoA allows comparing the partitioning of diversity at different levels of an organisational scale and the different facets of diversity. It is based on the matrix of pairwise distances (functional or phylogenetic) between species in a sample and an abundance matrix of such species. When the scope of the analysis is TD, all cells of the distance matrix are defined as 1 . Hence, all species are considered equally and maximally distant, and Rao's index becomes equal to the Simpson's index of diversity, i.e. equals to the probability that any two individuals randomly drawn from a community are of different species (Pavoine et al., 2004). Furthermore, the ordination of species according to the previous two matrices (i.e. pairwise distances and abundance) assembles species in a multivariate space related with the decomposition of diversity in organisational levels (Pavoine et al., 2004). Since the DPCoA only allows studying one factor at a time, we analysed the databases by season survey to avoid crossed factors.

Under the DPCoA framework we measured $\alpha$ diversity with function dpcoa in ade4. In order to examine the relationship between $\alpha$ diversity (i.e. parasite community in a host individual) and the factors host species (Case 1) or locality (Case 2), we used function 1m.rrpp 
257 of package RRPP (Collyer and Adams, 2018) that performs a linear model by residual 258 randomisation and provides empirical sampling distributions for further ANOVAs. Following 259 Collyer and Adams (2018), univariate $\alpha$ values were log-transformed. Then, we performed 260 ANOVAs (type I of sums of squares) using random distributions of the F-statistics (Collyer and Adams, 2018) for TD, FD and PPD, independently. When differences between samples from different host species or localities were significant, we ran posteriori pairwise comparisons of $\alpha$ TD, FD and PPD between host species or localities using function pairwise in RRPP.

We calculated $\beta$ diversity at two different organisational levels under the context of the Rao index of diversity. $\beta 1$ represents dissimilarity in parasite diversity among sampling units (hosts) within the same host species or locality. To calculate $\beta 2$, one must group together parasite communities of hosts of the same species or from the same locality and then, calculate dissimilarities in the parasite communities between different host species or localities. In both cases, we calculated $\beta$ diversities under the equivalent number approach (Ricotta and Szeidl, 2009) using the third proposition of the Rao index of diversity in Pavoine et al. (2016) (EqRao function in adiv (Pavoine, S., 2018. adiv: Analysis of diversity. R package version 1.2)). Indeed, this proposition is specifically developed for unbalanced samplings. Furthermore, we compared each of the TD, FD and PPD $\beta 1$ and $\beta 2$ diversities with 999 randomly simulated $\beta 1$ and $\beta 2$ values (rtestEqRao function in adiv) in order to establish whether the observed values significantly differ from those randomly simulated $(\mathrm{p}<0.05)$. When significant, we compared observed and simulated results to determine whether the observed $\beta 1$ or $\beta 2$ were greater or lower than expected at random. This allows determining whether parasite communities from fish of the same species or locality $(\beta 1)$ or of different fish species or locality $(\beta 2)$ are more similar (the observed value is lower than simulated values) or more dissimilar (the observed value is greater than simulated values) to each other than expected by chance. Finally, we used the standardised $\beta 1$ and $\beta 2$ given by EqRao function and defined as follows: (observed $\beta$ - mean of randomly simulated $\beta \mathrm{s}$ )/standard deviation of randomly simulated $\beta \mathrm{s}$. This standardisation enables us to infer if the parasite species, traits or the phylogenetic proxy are overdispersed 
(negative standardised $\beta$ ) or clustered (positive standardised $\beta$ ) (Head et al., 2018) within a level of a factor $(\beta 1)$ or between levels of a factor $(\beta 2)$.

\subsubsection{Influence of two crossed factors on diversity}

To evaluate and disentangle the effect of crossed factors on diversity, we used crossed-DPCoA (Pavoine et al., 2013a). In both case studies, we analysed the effect of two crossed factors simultaneously: host species (Case 1) or locality (Case 2), and season. The crossed-DPCoA is grounded on the DPCoA. It analyses the effect of two crossed factors at the same time. Thus, it distinguishes the proportional contribution of the sampling unit, each factor individually and the effect of the interaction of both factors on the diversity of the community. (2013a) terminology, each parasite community is associated with a component of the factor A (hosts species or locality) and a component of a factor B (season). The main version of the crossed-DPCoA plots the parasite species, the sampling units, and the variables of the main factor A, without taking into account seasonal differences (factor B), in a DPCoA space. Then, the first version of the crossed-DPCoA removes the amount of diversity among sampling units due to the sole effect of factor B, but retains combined effects of factors A and B (i.e. the interaction between factors $\mathrm{A}$ and $\mathrm{B}$ ). Finally, the second version of the crossed-DPCoA eliminates any influence of the factor B on the factor A (including the interaction term). Thus, it provides diversity exclusively under the light of the main crossed-factor, factor A (host species or locality). We carried out the main, the first and the second versions of the crossed-DPCoA with functions crossdpcoa_maineffect, crossdpcoa_version1 and crossdpcoa_version2 in adiv, respectively.

\section{Results}

Parasite functional and phylogenetic-like pairwise distance matrices were highly correlated (Mantel test, $\mathrm{F}=0.79, \mathrm{p}<0.001$ ). 
At $\alpha$ level and in the first survey (autumn 2004), we found non-significant differences in terms of TD and FD of parasites hosted by the different fish species (Table 2). However, the analysis of the PPD showed significant differences in $\alpha$ diversity among host species because the parasite community of $C$. ramada was less diverse than that of $M$. cephalus (Fig. 1: autumn 2004; Table 2; Supplementary Table S2 A). In the second survey (autumn 2005), $\alpha$ diversity of the parasite community of $C$. ramada was significantly lower in terms of parasite species (lowest TD) and functional traits (lowest FD) than the parasite communities hosted by other two fish species (Fig. 1: autumn 2005, Supplementary Table S2 B and C). As for PPD, the three host species displayed significantly different $\alpha$ diversity values with $C$. ramada having the lowest diversity and M. cephalus the highest (Fig. 1: autumn 2005; Table 2; Supplementary Table S2 D).

At $\beta 1$ level, we found that the parasite communities of fish from the same sample (within host species) tended to be more similar than expected by chance only in "TD - autumn 2004" (Table 3, Supplementary Fig. S1 A-C and Fig. S2 A-C). The negative values of the standardised $\beta 1$ in both autumn surveys indicated that parasite species, traits and phylogeny tended to be overdispersed within host species (Table 3). At $\beta 2$ level, the parasite communities from fish from different host species always differed significantly from randomness (Table 3, Supplementary Fig. S1 D-F and Fig. S2 D-F). The positive values of the standardised $\beta 2 \mathrm{~s}$ indicated that the composition in parasite species, traits and phylogenies differed between host species in both autumn surveys (Table 3 ).

When taking crossed-effects into account, diversity within each host individual constituted the highest proportion of parasite diversity in the whole community $(50 \%, 50 \%$ and 56\% for TD, FD and PPD respectively), followed by host species, the crossed effect of host species and seasons, and season (Table 4). The graphical representations of the second version of the crossed-DPCoA considering TD, FD and PPD (Fig. 2) were congruent. In all three cases, 
the first axis separated the parasite communities of the two coastal-related grey mullets $(C$.

ramada and $M$. cephalus) from the marine-related $C$. auratus, although those of $C$. ramada were always in an intermediate position. The parasite communities of the three host species showed an overlap in the parasite functional trait and phylogenetic-like spaces. However, host species was still a significant predictor for trait and phylogenetic diversity of the parasite communities (Fig. 2).

3.2. Case 2: parasite communities of Mugil cephalus from spring and autumn (2005) overlapped in TD, FD and PPD of marine localities (Ebro Delta Sea, Santa Pola Sea) but were separated from those of the lagoon (Santa Pola Lagoon)

The statistical analyses of $\alpha$ TD, FD and PPD did not show congruent results. In spring, localities did not differ in the composition of the parasite species (TD in Table 2) but did in FD and PPD. This was due to SPL being significantly less diverse than the other two localities in terms of FD and than EDS in terms of PPD (Table 2; Supplementary Table S3 A and B; Fig. 3: spring 2005). In the autumn survey (Fig. 3: autumn 2005), SPL had significantly lower TD than the other two localities (Supplementary Table S3 C). As for FD, the three localities differed significantly (Supplementary Table S3 D). For PPD, SPS had significantly higher diversity than the other two localities (Supplementary Table S3 E).

At $\beta 1$ level, the dissimilarity in diversity of the parasite communities from hosts within the same locality tended to be lower than expected by chance only for TD in both season surveys (Table 5, Supplementary Fig. S3 A-C and Fig. S4 A-C). The standardised observations with negative values indicated that parasite species, traits and the phylogenetic proxy were overdispersed within hosts from the same locality, except for "PPD - autumn" (Table 5). At $\beta 2$ level, differences in parasite diversity between localities always differed significantly from randomness (Table 5) and were always greater than expected (Supplementary Fig. S3 D-F and Fig. S4 D-F). The positive values of the standardised $\beta 2$ reflected that parasite species, traits and phylogeny were clustered at this level of the organisational scale. 

individual constituted the highest proportion of the parasite diversity in the whole community (58\% for TD, 54\% for FD and 52\% for PPD), followed by the crossed effect of locality and season, the locality and the season, for the three facets of diversity (Table 4). The graphical representation of the second version of the crossed-DPCoA displayed similar patterns for TD, FD and PPD (Fig. 4). The first axis slightly separated the diversity of parasite communities of the two marine localities (SPS and EDS) from the lagoon locality (SPL). Furthermore, both marine localities (EDS and SPS) overlapped substantially in the species (TD), trait (FD) and phylogenetic-like (PPD) spaces (Fig. 4).

\section{Discussion}

We examined the mechanisms driving the helminth parasite assemblages of grey mullets. Four main findings can be extracted from our results. First, the three facets of diversity (i.e. TD, FD and PPD) did not always show congruent results among them, which is unsurprising and follows the general trend reported for diverse groups of free-living organisms (e.g. Devictor et al., 2010; Hevia et al., 2016). However, these results have been hardly reported for parasite communities. Thus, conclusions of a parasite community study might be biased if any of the facets of diversity is overlooked (Jarzyna and Jetz, 2016). Second, the diversity of the parasite communities shows at least two opposed patterns (i.e. overdispersion and clustering). These patterns are found at different levels ( $\beta 1$ and $\beta 2$, respectively) of the two organisational scales (i.e. host species or locality). Third, the diversity of the two organisational scales is influenced by several variables. Fourth, the phylogenetic-like signal on functional traits suggested that functional traits are, at least, constrained by phylogeny. However, these two facets of diversity did not always display the same results, which suggests that the FD of this parasite community is not a surrogate of PPD (see Pavoine et al., 2013b).

At the lowest organisational level ( $\alpha$ diversity), the most notable case of incongruences among the three facets of diversity was the spring survey at SPL (Fig. 3), which was the richest in terms of number of species (highest TD) mainly because of trematodes. However, SPL 
displayed the lowest mean for $\alpha$ FD and $\alpha$ PPD probably because trematode species are redundant (sensu Carmona et al., 2016) in terms of FD and PPD. At the $\alpha$ level as well, we found that host individual explains for most of in its the three facets $(\sim 50 \%$ of the total diversity, crossed-DPCoA results), regardless of the case study considered. This strongly suggests that the parasite community found at each host individual ( $\alpha$ TD) is a random subset of a larger pool of parasite species within a host species or locality (Poulin, 1996). However, it also highlights that the parasite community found at this level is to a large extent a random subset of a larger pool of parasite ecological (FD) and evolutionary (PPD) strategies. This can be explained as $\alpha$ being product of random events (Poulin, 1996) or as result of several forces acting simultaneously in different directions in the development of parasite communities at $\alpha$ level (Poulin, 2005). However, it has been recently shown that $\alpha$ TD of parasite communities is determined by host age-class like an ecological succession of communities of free-living organisms. Thus, if hosts of different age-classes were analysed together it could mask an actual deterministic pattern of parasite community assemblage (Espínola-Novelo et al., 2020). Nonetheless, we consider that this is not a likely scenario in this study since parasite communities were mainly sampled from fish of two consecutive age-classes out of nine (classes 3 and 4 according to those described for M. cephalus in Espínola-Novelo et al., 2020).

In the case of $\beta 1$ diversity (within a host species or locality), differences among host individuals of the same species were less important than differences between host individuals of the same locality to determine the variation of the parasite communities (Table 4). In other words, host species is more determinant of the parasite community than locality, at least for TD since the parasite communities from different host species (Fig. 2) and localities (Fig. 3) are overlapped in FD and PPD spaces. In fact, the parasite community of grey mullets, especially monogeneans of genus Ligophorus (Dactylogyridae), tend to be host-species specific while they are not so geographically constrained within the Mediterranean Sea (e.g. Sarabeev et al., 2013). In addition, the negative standardised value of $\beta 1 \mathrm{TD}$ indicated that diversity of parasite

422 species were overdispersed within hosts from the same species, which may indicate that parasite species sharing the same resources are limited to coexist (e.g. Krasnov et al., 2005a). 
Nonetheless, parasite FD and PPD were randomly distributed among host individuals (Table 3 and 4). A similar result was found by Krasnov et al. (2005b). These authors proposed that when the number of parasite species infecting a host species becomes saturated, a random assemblage in PPD suggests that all the parasite species are ecologically interchangeable and contribute equally to the saturation. Here we show that FD and PPD are random assemblages. This would indicate that parasite species are functional and phylogenetic interchangeable entities. Furthermore, the span of the boxes (Fig. 1 and 3) and the size of the ellipses (Fig. 2 and 4) reflect the heterogeneity in infection among host individuals from the same species or locality. This could result from the almost universal observation of parasite aggregation among host individuals (Poulin, 2007a). Unfortunately, it is difficult to interpret the causes of parasite aggregation in host individuals in our system because we do not have enough data about inequality in environmental pressures among host individuals (Thieltges and Reise, 2007), host genetic background (Poulin, 2007a), host traits (Timi and Poulin, 2003) or parasite characteristics (such as dispersal ability) (Poulin, 2007b). indicated that species, traits and the proxy of the phylogeny were clustered, i.e. the species, trait, and phylogenetic compositions of parasite communities depend on the species host and the locality. Both environmental filtering and competition can be responsible for these patterns (Cadotte and Tucker, 2017). Moreover, intrahost speciation has also been pointed out as a cause of clustering in parasites (Krasnov et al., 2014). Parasite species competition is difficult to demonstrate (Mideo, 2009). However, the filtering of parasite species has received much more attention, particularly after the framework developed by Combes (2001). Due to the strong association between parasite and host species (Fig. 2), we consider that environmental (host) filtering is an important driver in these communities. As for intrahost speciation, it has been suggested for some Ligophorus spp. in our system (Blasco-Costa et al., 2012). Consequently, intrahost speciation could be an additional mechanism accounting for the clustering of such species. As for geographical differences in parasite assemblages, the overlap in the three spaces of diversity of the two marine localities was considerable (Fig. 4). This suggests that habitat 
condition (marine vs lagoon) is perhaps a stronger driver than geographical distance of the parasite communities. The environmental characteristics of the lagoon together with the high site fidelity of $M$. cephalus to lagoons (Chang et al., 2004) might eventually determine the slightly differentiated parasite community from SPL (Fig. 4). These results are indicative of environmental filtering in the parasite facets of diversity, which conforms with previous evidence only reported for TD of parasite communities of fish populations (e.g. Levy et al., 2019).

Finally, the season survey had a moderate effect on the parasite diversity of the host species and localities (crossed-DPCoA results). However, the capacity to differentiate parasite communities from different localities might be seasonal-dependent. Since freshwater effluents widely vary in EDS seasonally, and, thus, the parasite diversity in EDS and SPL localities could be more similar in some seasons than in others (Míguez-Lozano et al., 2012).

To sum up, our study supports the idea that the assembly rules driving parasite communities depend on the level of the analysis and the facet of diversity considered. Particularly, communities at host individual level appear to represent a random subset of parasite species of a larger pool of species, traits, and phylogeny of parasites. At intermediate levels, similar parasite species are limited to coexist, whereas at higher levels, the environment filters the parasite diversity, since a joint influence of host phylogenetic origin (Chelon vs Mugil) and environmental preferences (marine-related vs coastal-related) might drive the parasite TD, FD and PPD. Although this was less clear for the last two facets of diversity. Finally, the habitat conditions of the locality seem to be more determinant not only of the TD, but also of FD and PPD than geographic distance. The fact that diversity in these parasitic communities are subjected to random and deterministic processes simultaneously, but at different organisational levels, brings together Clements and Gleason ideas. These can be seen as two polar cases along a single deterministic-stochastic continuum of community organisation outcomes (Götzenberger et al., 2012; Liautaud et al., 2019). Clearly, parasitologists should pay attention to patterns of diversity at different facets and organisational levels. 
481 We thank Loreto Moñino Rodríguez and Kristi Lee for their laboratory assistance. This study is

482

483

484

485

486

487

488

489

490

491

492

493

494

495

496

497

498

499

500

501

502

503

504

505

506 part of the $\mathrm{PhD}$ thesis of CLB supported by a contract from Conselleria d'Educació, Investigació, Cultura i Esport (Generalitat Valenciana, Spain) and the European Social Fund (FSE) (ACIF/2016/374) and a visiting scholarship to the Muséum National d'Histoire Naturelle, Paris, France (BEFPI/2017/062). This study was funded by MINECO-FEDER, EU (CGL201571146-P). Conflict of interests: none.

\section{References}

Blasco-Costa, I., Míguez-Lozano, R., Sarabeev, V., Balbuena, J.A., 2012. Molecular phylogeny of species of Ligophorus (Monogenea: Dactylogyridae) and their affinities within the Dactylogyridae. Parasitol. Int. 61, 619-627.

Cadotte, M.W., Tucker, C.M., 2017. Should Environmental Filtering be Abandoned? Trends Ecol. Evol. 32, 429-437.

Cardona, L., 2001. Non-competitive coexistence between Mediterranean grey mullet: evidence from seasonal changes in food availability, niche breadth and trophic overlap. J. Fish Biol. 59, 729-744.

Cardona, L., 2006. Habitat selection by grey mullets (Osteichthytes: Mugilidae) in Mediterranean estuaries: the role of salinity. Sci. Mar. 70, 443-455.

Carmona, C.P., de Bello, F., Mason, N.W.H., Lepš, J., 2016. Traits Without Borders: Integrating Functional Diversity Across Scales. Trends Ecol. Evol. 31, 382-394.

Cavender-Bares, J., Keen, A., Miles, B., 2006. Phylogenetic structure of Floridian plant communities depends on taxonomic and spatial scale. Ecology 87, S109-S122.

Chang, C.W., lizuka, Y., Tzeng, W.N., 2004. Migratory environmental history of the grey mullet Mugil cephalus as revealed by otolith Sr:Ca ratios. Mar. Ecol. Prog. Ser. 269, 277-288.

Clarke, K.R., Warwick, R.M., 1998. A taxonomic distinctness index and its statistical properties. J. Appl. Ecol. 35, 523-531. 
507 Collyer, M.L., Adams, D.C., 2018. RRPP: An R package for fitting linear models to high-

508 dimensional data using residual randomization. Methods Ecol. Evol. 9, 1772-1779.

509 Combes, C., 2001. Parasitism. The ecology and evolution of intimate interactions. University of

510 Chicago Press, Chicago and London.

511 Devictor, V., Mouillot, D., Meynard, C., Jiguet, F., Thuiller, W., Mouquet, N., 2010. Spatial

512 mismatch and congruence between taxonomic, phylogenetic and functional diversity: the need

513 for integrative conservation strategies in a changing world. Ecol. Lett. 13, 1030-1040.

514 Durand, J.-D., Chen, W.-J., Shen, K.-N., Fu, C., Borsa, P., 2012. Genus-level taxonomic 515 changes implied by the mitochondrial phylogeny of grey mullets (Teleostei: Mugilidae). C. R. 516 Biol. 335, 687-697.

517 Espínola-Novelo, J.F., González, M.T., Pacheco, A.S., Luque, J.L., Oliva, M.E., 2020. Testing 518 for deterministic succession in metazoan parasite communities of marine fish. Ecol. Lett. 23, $519 \quad 631-641$.

520 Euzet, L., Combes, C., 1969. Contribution a l'etude des Microcotylidae (Monogenea), parasites 521 de Mugil cephalus L. (Teleostei). Parazitol. Sb. 24, 91-105.

522 Gaevskaya, A.V., Dmitrieva, E.V., 1992. Haplosplanchnus pachysomus (Trematoda: 523 Haplosplanchnidae) -A parasite of Black Sea mullets. Parazitologiya 26, 385-388. (In Russian) 524 Götzenberger, L., de Bello, F., Bråthen, K.A., Davison, J., Dubuis, A., Guisan, A., Lepš, J., 525 Lindborg, R., Moora, M., Pärtel, M., Pellissier, L., Pottier, J., Vittoz, P., Zobel, K., Zobel, M., 526 2012. Ecological assembly rules in plant communities-approaches, patterns and prospects. Biol. 527 Rev. 87, 111-127.

528 Gower, J.C., 1971. A General Coefficient of Similarity and Some of Its Properties. Biometrics 529 $27,857-871$.

530 Gower, J.C., Legendre, P., 1986. Metric and Euclidean properties of dissimilarity coefficients. J. 531 Classif. 3, 5-48.

532 Guisan, A., Rahbek, C., 2011. SESAM - a new framework integrating macroecological and 533 species distribution models for predicting spatio-temporal patterns of species assemblages. J. 534 Biogeogr. 38, 1433-1444. 

M.B., 2018. Trait and phylogenetic diversity provide insights into community assembly of reefassociated shrimps (Palaemonidae) at different spatial scales across the Chagos Archipelago. Ecol. Evol. 8, 4098-4107.

Hevia, V., Carmona, C.P., Azcárate, F.M., Torralba, M., Alcorlo, P., Ariño, R., Lozano, J.,

540 Castro-Cobo, S., González, J.A., 2016. Effects of land use on taxonomic and functional

541 diversity: a cross-taxon analysis in a Mediterranean landscape. Oecologia 181, 959-970.

542 Jarzyna, M.A., Jetz, W., 2016. Detecting the Multiple Facets of Biodiversity. Trends Ecol. Evol. $543 \quad 31,527-538$.

544 Kraft, N.J.B., Ackerly, D.D., 2010. Functional trait and phylogenetic tests of community assembly across spatial scales in an Amazonian forest. Ecol. Monogr. 80, 401-422. Krasnov, B.R., Mouillot, D., Shenbrot, G.I., Khokhlova, I.S., Poulin, R., 2005a. Abundance patterns and coexistence processes in communities of fleas parasitic on small mammals. Ecography (Cop.). 28, 453-464.

Krasnov, B.R., Pilosof, S., Stanko, M., Morand, S., Korallo-Vinarskaya, N.P., Vinarski, M.V., Poulin, R., 2014. Co-occurrence and phylogenetic distance in communities of mammalian ectoparasites: limiting similarity versus environmental filtering. Oikos 123, 63-70. Krasnov, B.R., Shenbrot, G.I., Khokhlova, I.S., Degen, A.A., 2016. Trait-based and phylogenetic associations between parasites and their hosts: a case study with small mammals and fleas in the Palearctic. Oikos 125, 29-38. Assembly rules of ectoparasite communities across scales: combining patterns of abiotic factors, host composition, geographic space, phylogeny and traits. Ecography 38, 184-197. variation in species diversity and composition of flea assemblages in small mammalian hosts:

560 geographical distance or faunal similarity? J. Biogeogr. 32, 633-644.

561 Levy, E., Canel, D., Rossin, M.A., Hernández-Orts, J.S., González-Castro, M., Timi, J.T., 2019.

562 Parasites as indicators of fish population structure at two different geographical scales in 
563

564

565

566

567

568

569

570

571

572

573

574

575

576

577

578

579

580

581

582

583

584

585

586

587

588

589

contrasting coastal environments of the south-western Atlantic. Estuar. Coast. Shelf Sci. 229, 106400.

Liautaud, K., van Nes, E.H., Barbier, M., Scheffer, M., Loreau, M., 2019. Superorganisms or loose collections of species? A unifying theory of community patterns along environmental gradients. Ecol. Lett. 22, 1243-1252.

Llopis-Belenguer, C., Balbuena, J.A., Lange, K., de Bello, F., Blasco-Costa, I., 2019. Towards a unified functional trait framework for parasites. Trends Parasitol. 35, 972-982

Llopis-Belenguer, C., Blasco-Costa, I., Balbuena, J.A., 2018. Evaluation of three methods for biomass estimation in small invertebrates, using three large disparate parasite species as model organisms. Sci. Rep. 8, 3897.

Mayfield, M.M., Levine, J.M., 2010. Opposing effects of competitive exclusion on the phylogenetic structure of communities. Ecol. Lett. 13, 1085-1093.

Mideo, N., 2009. Parasite adaptations to within-host competition. Trends Parasitol. 25, 261-268.

Míguez-Lozano, R., Pardo-Carranza, T.V., Blasco-Costa, I., Balbuena, J.A., 2012. Spatial structure of helminth communities in the golden grey mullet, Liza aurata (Actinopterygii: Mugilidae), from the Western Mediterranean. J. Parasitol. 98, 904-912.

Mouillot, D., Šimková, A., Morand, S., Poulin, R., 2005. Parasite species coexistence and limiting similarity: a multiscale look at phylogenetic, functional and reproductive distances. Oecologia 146, 269-278.

Orecchia, P., Paggi, L., 1987. Cucullanus bioccai n. sp. (Nematoda: Cucullanidae), parassita di Mugil cephalus L. Parassitologia 29, 71-74.

Orecchia, P., Paggi, L., Radujkovic, B., 1988. Sur une nouvelle espèce d' Eoacanthocéphale Acanthogyrus (Acanthosentis) lizae n. sp. (Gyracanthocephala, Quadrigyridae) parasite de Liza aurata (Risso). Bull. Mus. natn. Hist. nat., Paris, $4^{\mathrm{e}}$ sér., 10, 529-534.

Paperna, I., 1964. Parasitic helminths of inland-water fishes in israel. Isr. J. Zool. 13, 1-26.

Pavoine, S., Bonsall, M.B., 2011. Measuring biodiversity to explain community assembly: a unified approach. Biol. Rev. 86, 792-812. 

analysing interacting factors affecting biodiversity patterns: crossed-DPCoA. PLoS One 8,

592

593

594

595

596

597 e54530.

Pavoine, S., Dufour, A.-B., Chessel, D., 2004. From dissimilarities among species to dissimilarities among communities: a double principal coordinate analysis. J. Theor. Biol. 228, $523-537$.

Pavoine, S., Gasc, A., Bonsall, M.B., Mason, N.W.H., 2013b. Correlations between phylogenetic and functional diversity: mathematical artefacts or true ecological and evolutionary processes? J. Veg. Sci. 24, 781-793.

Pavoine, S., Love, M.S., Bonsall, M.B., 2009a. Hierarchical partitioning of evolutionary and ecological patterns in the organization of phylogenetically-structured species assemblages: application to rockfish (genus: Sebastes) in the Southern California Bight. Ecol. Lett. 12, 898908.

Pavoine, S., Marcon, E., Ricotta, C., 2016. 'Equivalent numbers' for species, phylogenetic or functional diversity in a nested hierarchy of multiple scales. Methods Ecol. Evol. 7, 1152-1163. Pavoine, S., Vallet, J., Dufour, A.-B., Gachet, S., Daniel, H., 2009b. On the challenge of treating various types of variables: application for improving the measurement of functional diversity. Oikos 118, 391-402.

Poulin, R., 1996. Richness, nestedness, and randomness in parasite infracommunity structure. Oecologia 105, 545-551.

Poulin, R., 2005. Structure of parasite communities. In: Rohde, K. (Ed.), Marine Parasitology. CABI Publishing, Wallingford, pp. 309-315.

Poulin, R., 2007a. Are there general laws in parasite ecology? Parasitology 134, 763-776.

Poulin, R., 2007b. The structure of parasite communities in fish hosts: Ecology meets geography and climate. Parassitologia 49, 169-172.

Poulin, R., Valtonen, E.T., 2001. Nested assemblages resulting from host size variation: the case of endoparasite communities in fish hosts. Int. J. Parasitol. 31, 1194-1204. 
617 Rao, C.R., 1982. Diversity and dissimilarity coefficients: A unified approach. Theor. Popul.

618 Biol. 21, 24-43.

619 Ricklefs, R.E., 2008. Disintegration of the ecological community. Am. Nat. 172, 741-750.

620 Ricotta, C., Szeidl, L., 2009. Diversity partitioning of Rao's quadratic entropy. Theor. Popul.

621 Biol. 76, 299-302.

622 Sarabeev, V.L., Rubtsova, N.Y., Yang T., Balbuena J.A., 2013. Taxonomic revision of the

623 Atlantic and Pacific species of Ligophorus Euzet and Suriano, 1977 (Monogenea:

624 Dactylogyridae) from mullets (Teleostei: Mugilidae) with proposal of a new genus and 625 description of four new species. Vestn. Zool. S28, 1-112.

626 Thieltges, D.W., Reise, K., 2007. Spatial heterogeneity in parasite infections at different spatial 627 scales in an intertidal bivalve. Oecologia 150, 569-581.

628 Thioulouse, J., Dray, S., Dufour, A.-B., Siberchicot, A., Jombart, T., Pavoine, S., 2018.

629 Multivariate Analysis of Ecological Data with ade4. Springer New York, New York.

630 Timi, J.T., Poulin, R., 2003. Parasite community structure within and across host populations of 631 a marine pelagic fish: How repeatable is it? Int. J. Parasitol. 33, 1353-1362.

632 Tkach, I.V., Sarabeev, V.L., Shvetsova, L.S., 2014. Taxonomic status of Neoechinorhynchus 633 agilis (Acanthocephala, Neoechinorhynchidae), with a description of two new species of the 634 genus from the Atlantic and Pacific Mullets (Teleostei, mugilidae). Vestn. Zool. 48, 291-306.

635 Yamaguti, S., 1958. Systema Helmintum - Volume I - The Digenetic Trematodes of 636 Vertebrates, Part I, II. Interscience Publishers, New York. 
Taxonomic

Functional

Phylogenetic Proxy
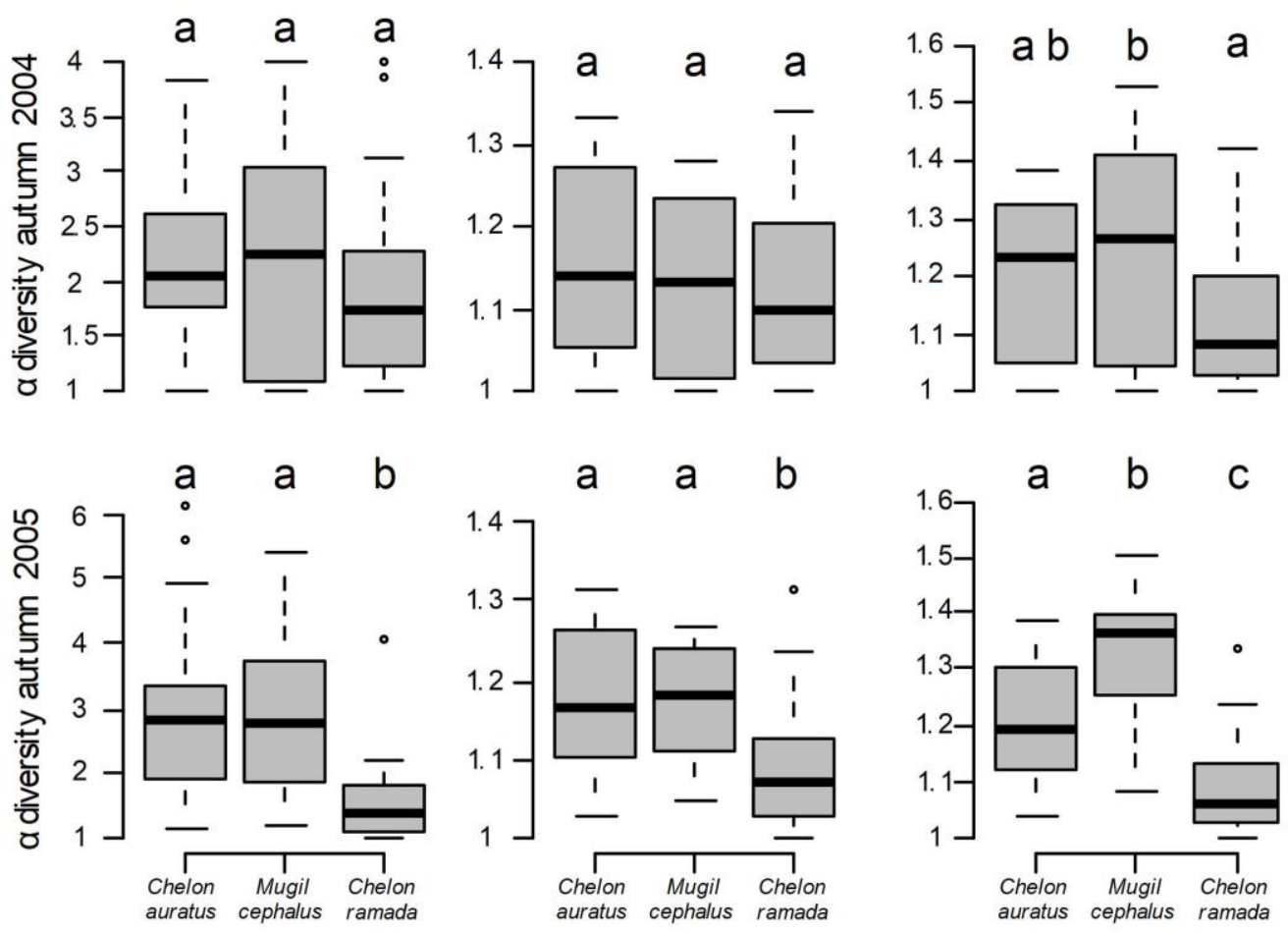

Host species

Host species

Host species

638

639 Fig. 1. Parasite $\alpha$ diversity in terms of taxonomic (TD), functional (FD) and a proxy of the 640 phylogenetic (PPD) diversity for each host individual of each fish species (Case 1). 641 Different lowercase letters indicate significant differences between host species. 


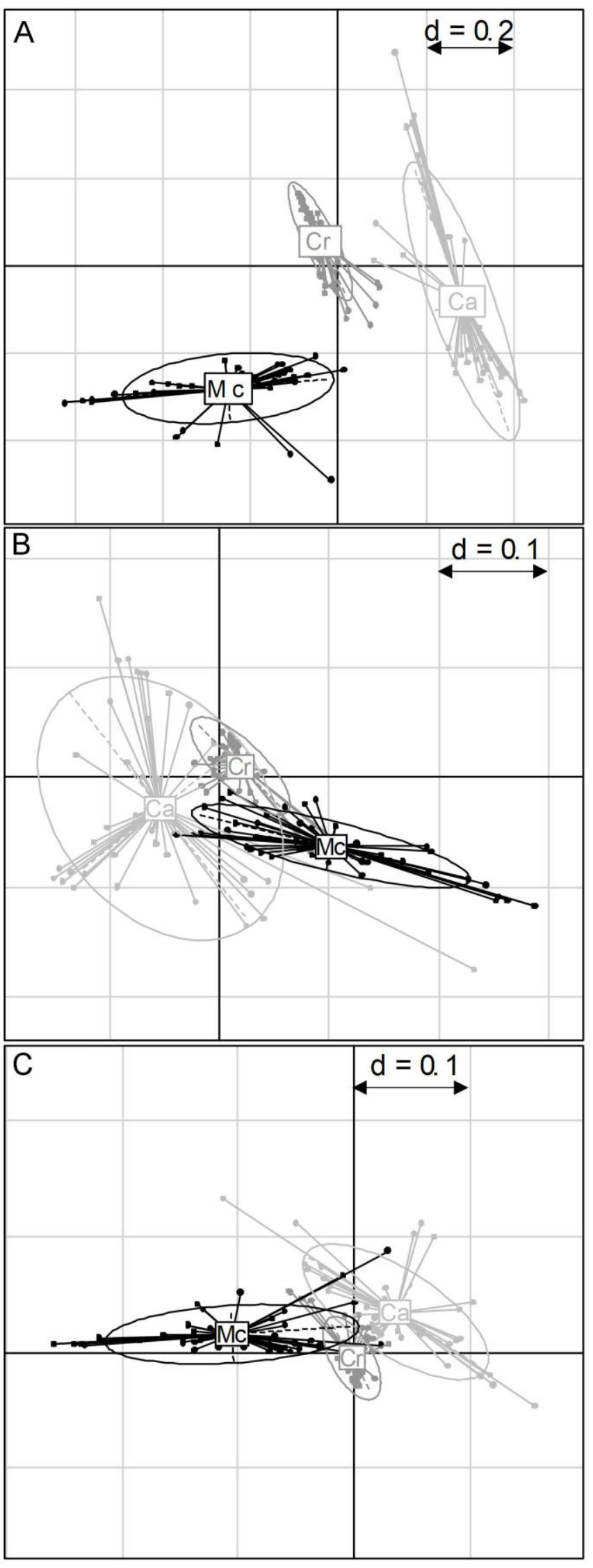



trait space, and (C) parasite phylogenetic-like space (Case 1). Fish are grouped by host species. Abbreviations: $\mathrm{Mc}, \mathrm{Cr}$ and $\mathrm{Ca}$ represent the centroid of each fish species, and stand for Mugil cephalus, Chelon ramada and C. auratus, respectively. These analyses were carried out with the second version of the crossed-DPCoA. The width and height of the ellipses are given by the variance of the coordinates of the individuals, and the covariance between the coordinates on the two axes gives the slope of the ellipse. "d" (top-right) indicates the length of 651 the side of the grey squares of the background grid.
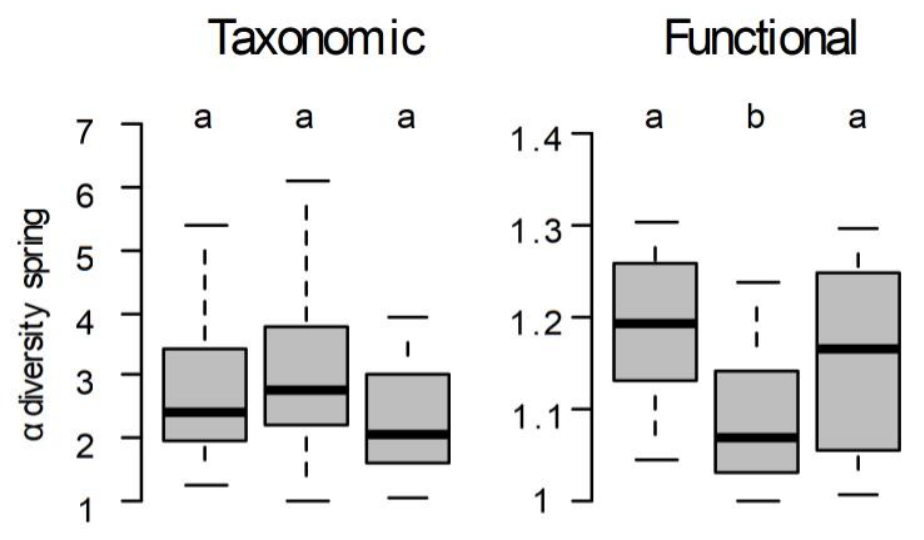

\section{Phylogenetic Proxy}
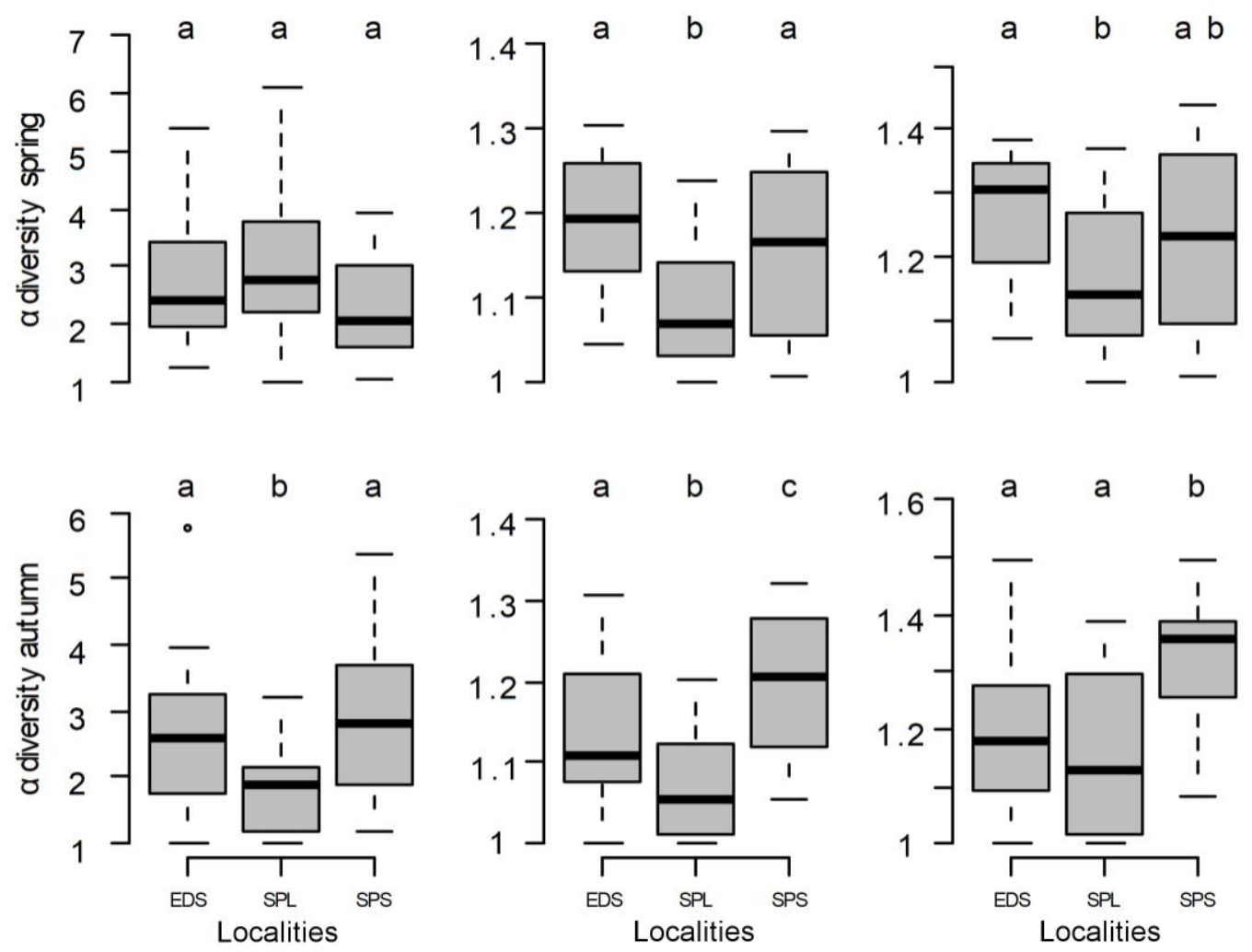

653

Fig. 3. Parasite $\alpha$ diversity in terms of taxonomic (TD), functional (FD) and a proxy of the phylogenetic (PPD) diversity for each locality (Case 2). Different lowercase letters indicate significant differences between localities. Abbreviations: EDS, Ebro Delta Sea; SPS, Santa Pola Sea; SPL, Santa Pola Lagoon. 

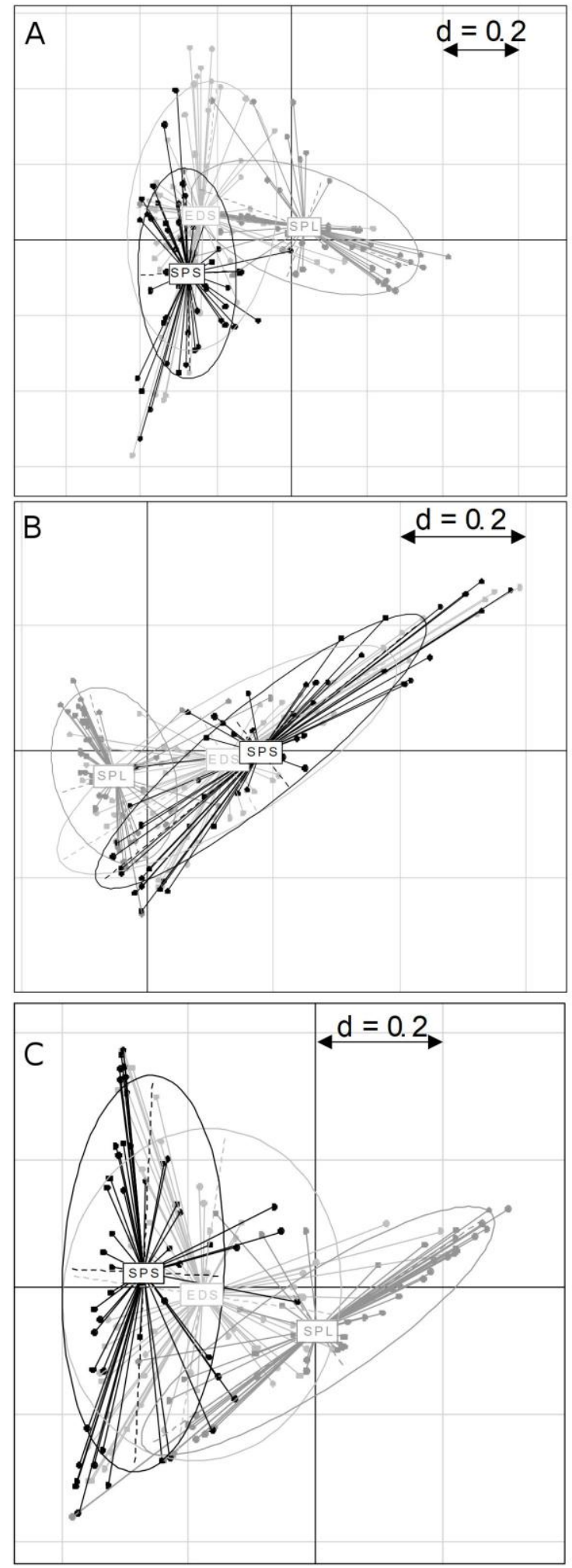

660 Fig. 4. Position of each host individual (dots) in the (A) parasite species space, (B) parasite trait space and (C) parasite phylogenetic-like space (Case 2). Fish were grouped by localities. Abbreviations: EDS, SPL and SPS represent the centroid of each locality, and stand 
663 for Ebro Delta Sea, Santa Pola Lagoon and Santa Pola Sea, respectively. These analyses were 664 carried out with the second version of the crossed-DPCoA. The width and height of the ellipses 665 are given by the variance of the coordinates of the individuals, and the covariance between the 666 coordinates on the two axes gives the slope of the ellipse. "d" (top-right) indicates the length of 667 the side of the grey squares of the background grid. 

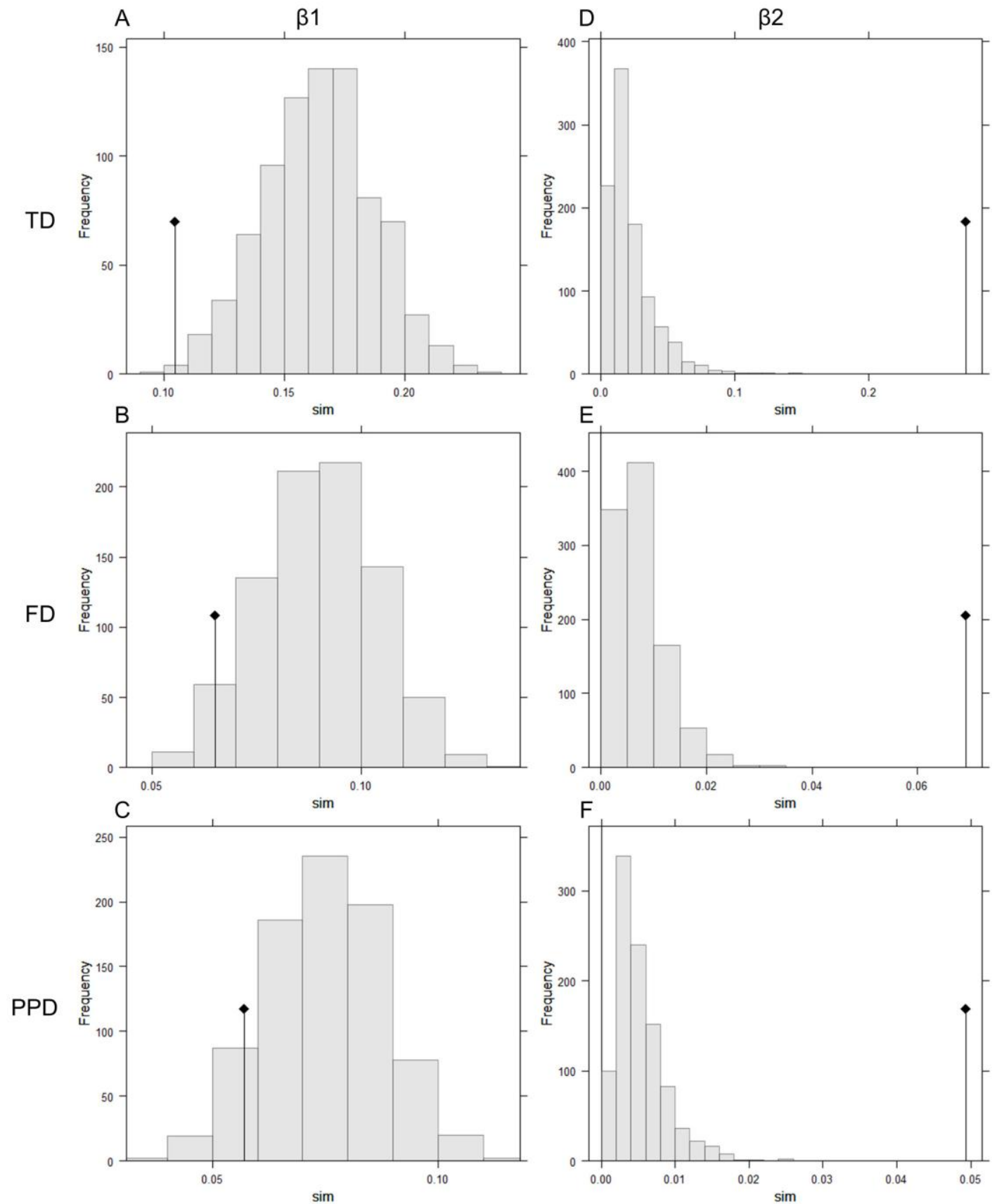

670

671 Supplementary Figure S1. Observed and simulated $\beta$ diversity values (Case 1: autumn 2004). (A, B, C) $\beta 1$ diversity or extent of dissimilarity in the diversity of parasite communities among host individuals within each host species (Chelon auratus, Mugil cephalus and Chelon ramada). (D, E, F) $\beta 2$ diversity or extent of dissimilarity in the diversity of parasite communities between host species. Diversity was measured in terms of (A, D) Taxonomic 
677 (PPD). Samples are from Santa Pola Sea and autumn 2004 (Case 1). Observed $\beta$ values (black 678 diamond on the top of the black vertical line) and distribution of the simulated (x-axis: sim) $\beta$ 679 values (grey bars).

680
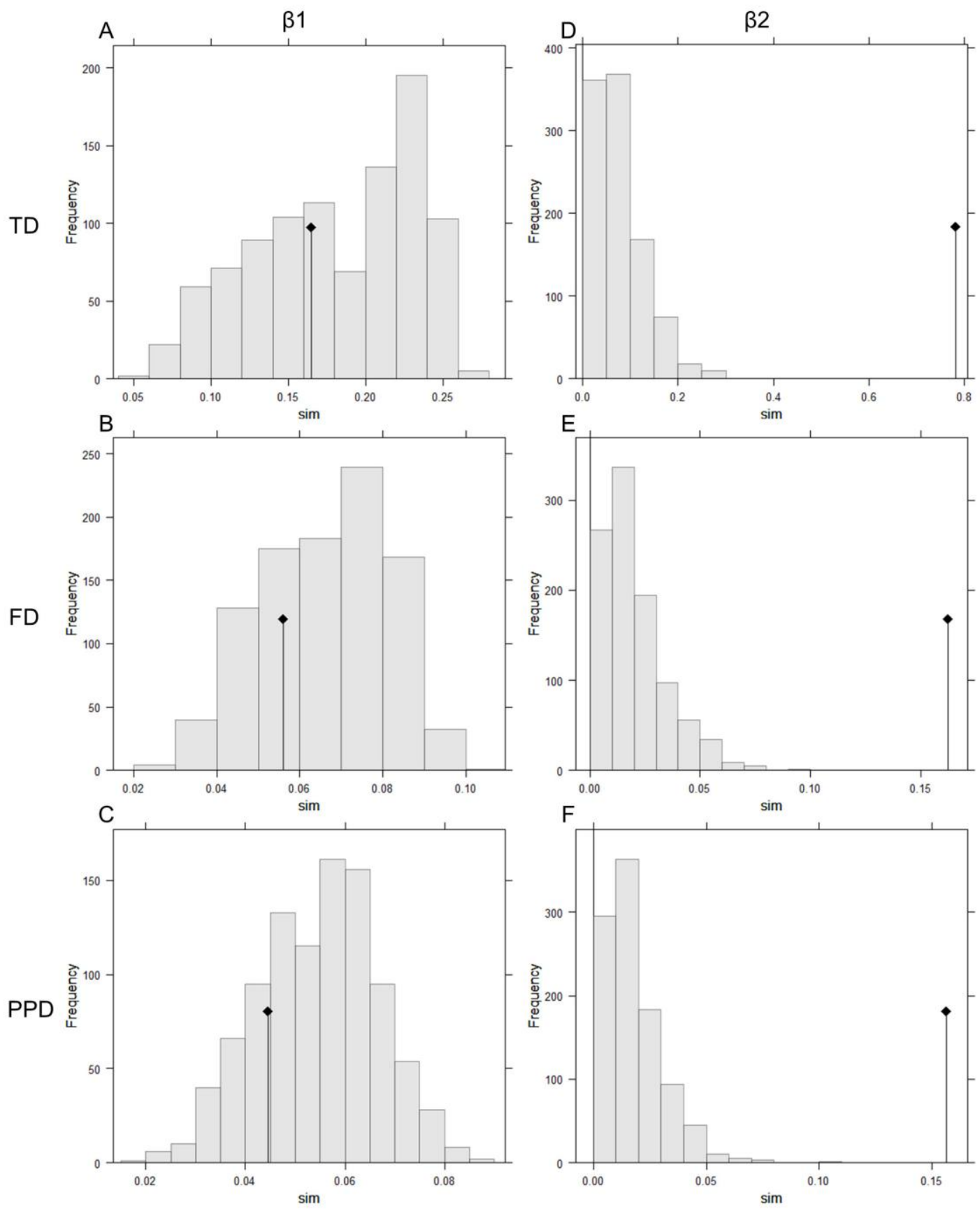

682 Supplementary Figure S2. Observed and simulated $\beta$ diversity values (Case 1: autumn

2005). (A, B, C) $\beta 1$ diversity or extent of dissimilarity in the diversity of parasite communities 
684 among host individuals within each host species (Chelon auratus, Mugil cephalus and Chelon 685 ramada). (D, E, F) $\beta 2$ diversity or extent of dissimilarity in the diversity of parasite 686 communities between host species. Diversity was measured in terms of (A, D) Taxonomic 687 Diversity (TD), (B, E) Functional Diversity (FD) and (C, F) the Proxy of Phylogenetic Diversity 688 (PPD). Samples are from Santa Pola Sea and autumn 2005 (Case 1). Observed $\beta$ values (black 689 diamond on the top of the black vertical line) and distribution of the simulated (x-axis: sim) $\beta$ 690 values (grey bars).

691 

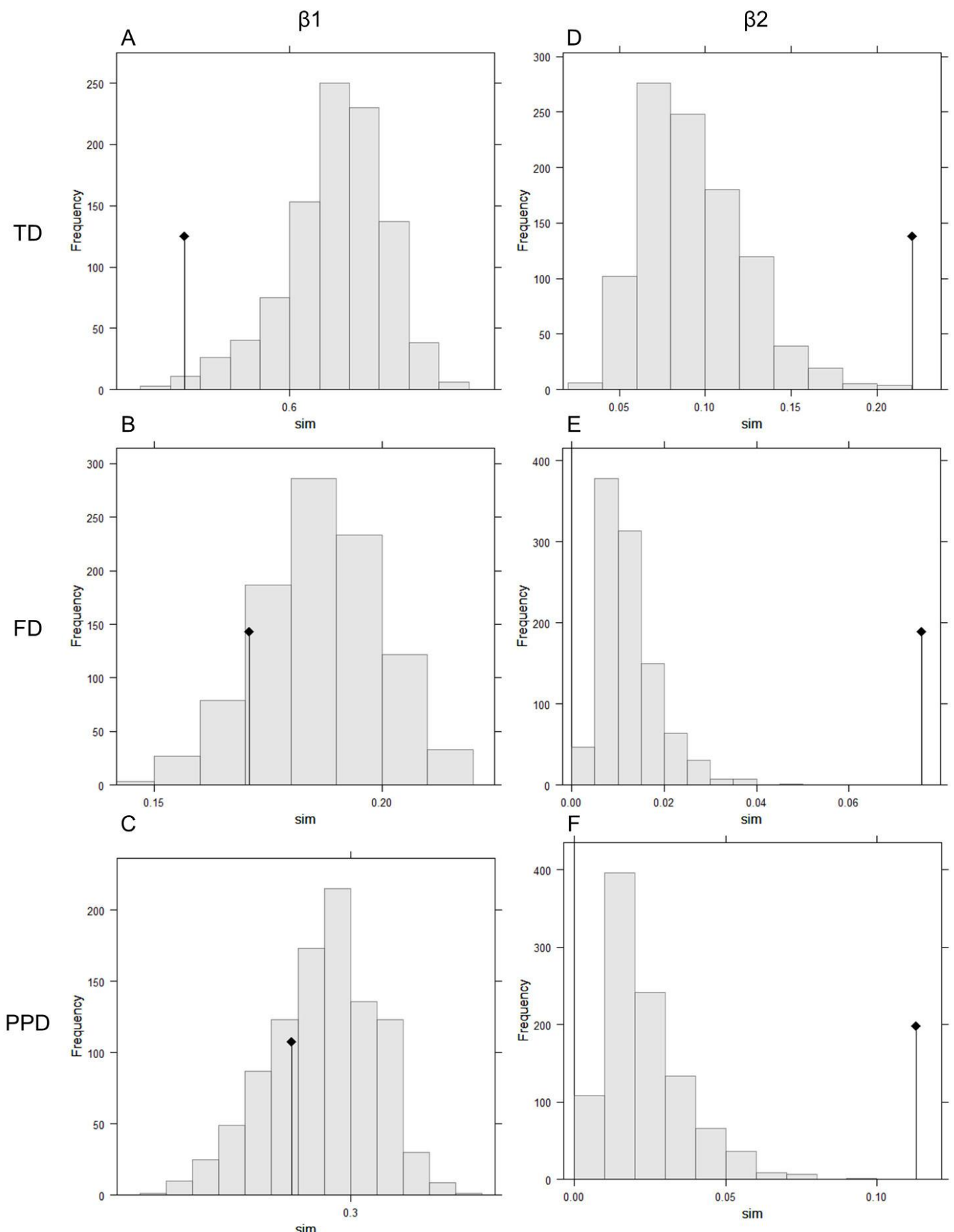

692

$\operatorname{sim}$

693 Supplementary Fig S3. Observed and simulated $\beta$ diversity values (Case 2: spring 2004).

694 (A, B , C) $\beta 1$ diversity or extent of dissimilarity in the diversity of parasite communities among 695 host individuals within each locality (Ebro Delta Sea, Santa Pola Lagoon and Santa Pola Sea). (D, E, F) $\beta 2$ diversity or extent of dissimilarity in the diversity of parasite communities between

697 localities. Diversity was measured in terms of (A, D) Taxonomic Diversity (TD), (B, E) Functional Diversity (FD) and (C, F) the Proxy of Phylogenetic Diversity (PPD). Samples are of 

diamond on the top of the black vertical line) and distribution of the simulated (x-axis: sim) $\beta$

701 values (grey bars).

702
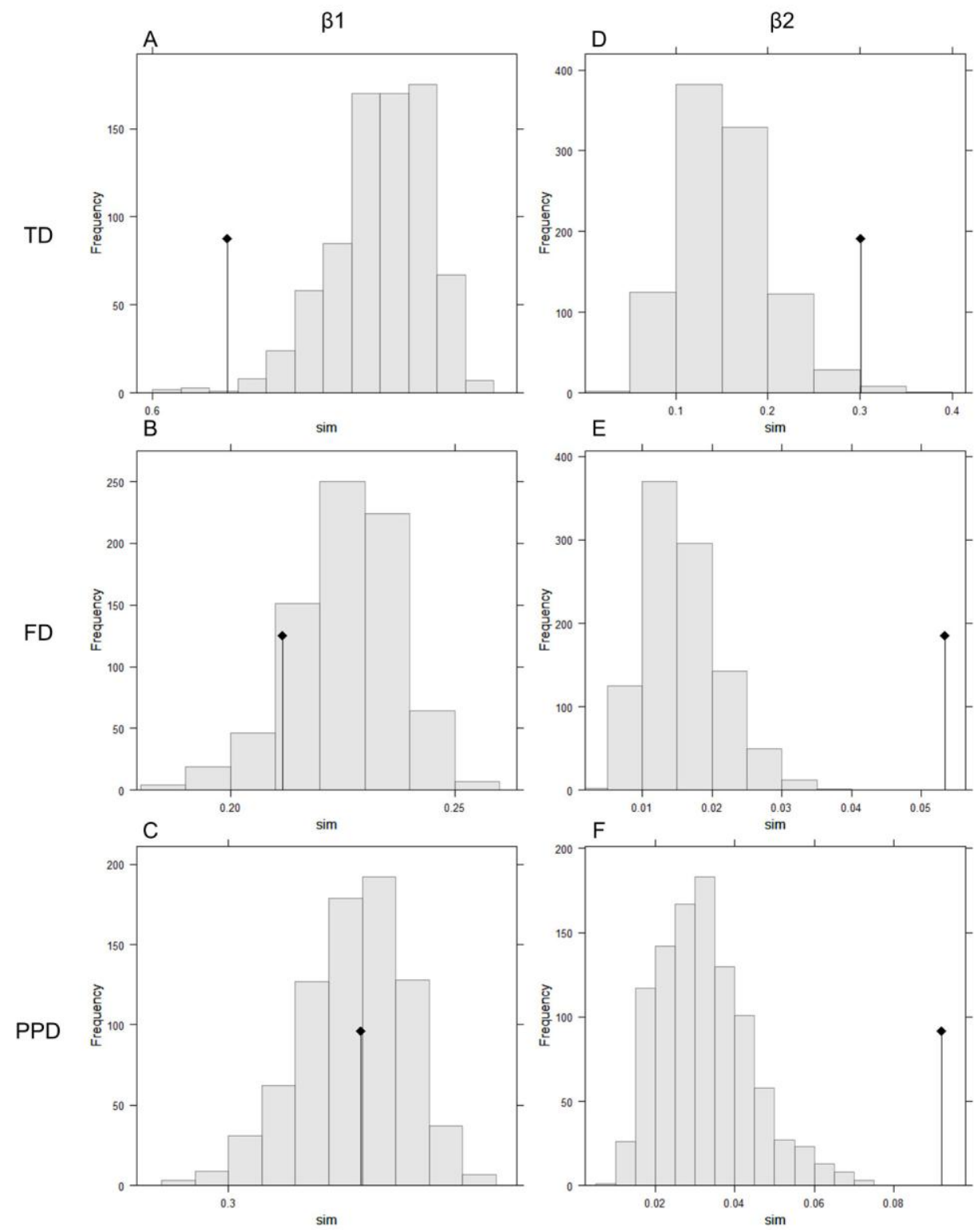

703

Supplementary Fig S4. Observed and simulated $\beta$ diversity values (Case 2: autumn 2005).

(A, B, C) $\beta 1$ diversity or extent of dissimilarity in the diversity of parasite communities among host individuals within each locality (Ebro Delta Sea, Santa Pola Lagoon and Santa Pola Sea). (D, E, F) $\beta 2$ diversity or extent of dissimilarity in the diversity of parasite communities between localities. Diversity was measured in terms of (A, D) Taxonomic Diversity (TD), (B, E) 
709 Functional Diversity (FD) and (C, F) the Proxy of Phylogenetic Diversity (PPD). Samples are of 710 the host species Mugil cephalus and from autumn 2005 (Case 2). Observed $\beta$ values (black 711 diamond on the top of the black vertical line) and distribution of the simulated (x-axis: sim) $\beta$ 712 values (grey bars). 
713 Tables

714 Table 1. Sample summary. Fish (host individuals) sample sizes by host species, seasons, and 715 localities.

\begin{tabular}{cccccccccc} 
& \multicolumn{3}{c}{ Santa Pola Sea } & \multicolumn{3}{c}{ Santa Pola Lagoon } & \multicolumn{3}{c}{ Ebro Delta Sea } \\
& $\begin{array}{c}\text { Autumn } \\
2004\end{array}$ & $\begin{array}{c}\text { Spring } \\
2005\end{array}$ & $\begin{array}{c}\text { Autumn } \\
2005\end{array}$ & $\begin{array}{c}\text { Autumn } \\
2004\end{array}$ & $\begin{array}{c}\text { Spring } \\
2005\end{array}$ & $\begin{array}{c}\text { Autumn } \\
2005\end{array}$ & $\begin{array}{c}\text { Autumn } \\
\text { 2004 }\end{array}$ & Spring & Autumn \\
\hline $\begin{array}{c}\text { Chelon } \\
\text { auratus }\end{array}$ & 12 & & 30 & & & & & & \\
$\begin{array}{c}\text { Mugil } \\
\text { cephalus }\end{array}$ & 20 & 22 & 30 & & 25 & 31 & & 28 & 29 \\
$\begin{array}{c}\text { Chelon } \\
\text { ramada }\end{array}$ & 30 & & 15 & & & & & & \\
\hline
\end{tabular}

716 
717 Table 2. Results of Type I ANOVAs of $\alpha$ Taxonomic (TD), Functional (FD) and Proxy of

718 Phylogenetic (PPD) diversity. $P$ values are given (significance level $P<0.05$ ).

Case $1 \quad$ Case 2

\begin{tabular}{ccccc} 
& $\begin{array}{c}\text { Autumn } \\
2004\end{array}$ & $\begin{array}{c}\text { Autumn } \\
2005\end{array}$ & $\begin{array}{c}\text { Spring } \\
2005\end{array}$ & $\begin{array}{c}\text { Autumn } \\
2005\end{array}$ \\
\hline TD & 0.447 & 0.001 & 0.16 & 0.001 \\
FD & 0.693 & 0.002 & 0.001 & 0.001 \\
& & & & \\
PPD & 0.023 & 0.001 & 0.03 & 0.001 \\
\hline
\end{tabular}

719 
721 1). Statistical results of the partitioning of Taxonomic (TD), Functional (FD) and the Proxy of 722 Phylogenetic (PPD) Diversity at two organisational levels ( $\beta 1$ [among host individuals within 723 host species] and $\beta 2$ [between host species]) in comparison to a distribution of 999 random 724 replicates. $P$ values are given (significance level $P<0.05$ ). Standardised observed values are 725 given in parenthesis. Standardised $\beta$ is negative when the community structure is overdispersed, 726 and positive when the community structure is clustered.

\begin{tabular}{ccccccc} 
& \multicolumn{3}{c}{$\beta 1$} & & $\beta 2$ & \\
& TD & FD & PPD & TD & FD & PPD \\
\hline autumn 2004 & 0.007 & 0.07 & 0.17 & 0.001 & 0.001 & 0.001 \\
& $(-2.6)$ & $(-1.8)$ & $(-1.4)$ & $(14.6)$ & $(13)$ & $(13.3)$ \\
autumn 2005 & 0.85 & 0.61 & 0.42 & 0.001 & 0.001 & 0.001 \\
& $(-0.3)$ & $(-0.7)$ & $(-0.8)$ & $(13.8)$ & $(10.1)$ & $(11.2)$ \\
\hline
\end{tabular}

727 
728 Table 4. Percentage of diversity associated with each factor. Taxonomic (TD), Functional

729 (FD) and Proxy of Phylogenetic (PPD) Diversity of parasite communities (A) of three host 730 species and autumn 2004 and 2005 (Case 1); (B) and from three localities and spring and 731 autumn 2005 (Case 2).

\begin{tabular}{lcll} 
A & TD & FD & PPD \\
\hline Host individual & 50.3 & 50.2 & 56.3 \\
Host species & 31.3 & 28 & 20.6 \\
Season & 1.6 & 2.1 & 1.5 \\
Host species $\times$ season & 16.8 & 19.7 & 21.6 \\
\hline B & & & \\
\hline Host individual & 57.9 & 53.7 & 52.1 \\
Locality & 5.8 & 12.4 & 12.1 \\
Season & 1.3 & 0.6 & 1 \\
Locality $\times$ Season & 35 & 33.3 & 34.8 \\
\hline
\end{tabular}

732 
734 Statistical results of the partitioning of Taxonomic (TD), Functional (FD) and Proxy of 735 Phylogenetic (PPD) Diversity at two organisational levels ( $\beta 1$ [among host individuals within 736 locality] and $\beta 2$ [between localities]) in comparison to a distribution of 999 random replicates. $P$ 737 values are given (significance level $P<0.05$ ). Standardised observed values are given in 738 parenthesis. A standardised $\beta$ is negative when the community structure is overdispersed, and 739 positive when the community structure is clustered.
$\beta 1$
$\beta 2$

TD

FD

PPD

\begin{tabular}{lcccccc}
\hline spring 2005 & 0.01 & 0.25 & 0.57 & 0.001 & 0.001 & 0.001 \\
& $(-2.9)$ & $(-1.2)$ & $(-0.6)$ & $(4.3)$ & $(10.2)$ & $(6.7)$ \\
autumn 2005 & 0.01 & 0.2 & 0.91 & 0.01 & 0.001 & 0.001 \\
& $(-3.2)$ & $(-1.2)$ & $(0.1)$ & $(3)$ & $(7)$ & $(5.2)$ \\
\hline
\end{tabular}

740 